\title{
GOMENTARIO DE JURISPRUDENCIA
}

\section{La Sentencia del Tribunal Constitucional 236/2015, de 19 de noviembre de 2015 sobre la Ley 1/2011, de 17 de febrero, de Reordenación del Sector Público de Andalucía. (y Damocles guardó la espada)}

$$
\text { José Ortiz Mallol }
$$

Letrado de la Junta de Andalucía

\begin{abstract}
I. INTRODUCGIÓN II. CONTEXTO JURISDCGIONAL. 1. Precedentes. 2. Secuelas de la Sentencia 236/15. III. LA SENTENCIA. 1. Motivos del recurso y posicionamiento de las partes 2. Posición del Tribunal Constitucional en relación con los distintos motivos del recurso. 3. Los votos particulares. IV. A MODO DE CODA
\end{abstract}

\section{RESUMEN}

Este comentario analiza la sentencia del Tribunal Constitucional 236/2015 que declara la constitucionalidad de la ley 1/2011, de Reordenación del sector público de Andalucía. La Sentencia es el punto final a un intenso debate en las diversas instancias judiciales, viniendo a confirmar la posición del Tribunal Supremo al declarar la legalidad de las diversas disposiciones dictadas a su amparo.

ABSTRACT

This commentary discusses the Constitutional Court ruling 236/2015 declaring the constitutionality of the law 1/2011 of reordering the public sector in Andalusia. Judgment is the end to an intense debate in the various courts, coming to confirm the position of the Supreme Court to declare the legality of the various regulations issued thereunder. 


\section{INTRODUCGIÓN}

La Sentencia del Tribunal Constitucional 236/2015, sobre la ley 1/2011, de Reordenación del sector público de Andalucía, es de las que valen tanto por lo que evita como por lo que asienta. Compartir la verdad de esta frase, que pudiera parecer excesiva, es más fácil si se conoce bien lo que estaba en juego.

Es sabido que el proceso de reordenación del sector público de Andalucía tiene por base normativa la ley $1 / 2011$, la cual es consecuencia directa del Decreto-Ley 5/2010, complementado mediante el Decreto-Ley 6/2010, aprobado como proyecto de ley en sesión plenaria del Parlamento de Andalucía los días 16 y 17 de febrero de 2011. El proceso de reordenación ha supuesto, desde la estricta esfera normativa, la aprobación de un amplísimo grupo de Estatutos de las Agencias Públicas creadas) ${ }^{1}$; lo cual, desde la esfera organizativa, ha significado la transformación de entidades instrumentales privadas en agencias públicas, con todo lo que ello significa en orden a cambios estructurales en la manera de organizarse y de actuar. En suma, un proceso que ha afectado a miles de trabajadores públicos y - lo más significativo- este proceso de publificación de las entidades instrumentales andaluzas ha tenido una influencia directa en el conjunto de ciudadanos andaluces que han pasado de ser parte de relaciones jurídico-privadas con aquellas sociedades mercantiles y fundaciones de mano pública a ser administrados, con una fuerte posición jurídico-pública en relación con las Agencias creadas para la realización de las funciones que aquéllas desempeñaban.

La citada ley -y sus Decretos leyes antecesores- fueron objeto de una cierta contestación social ${ }^{2}$ promovida por algunas organizaciones sindicales ligadas a la defensa de los derechos de los funcionarios de carrera. Ante todo, debe tenerse en cuenta

${ }^{1}$ Como meros ejemplos, Decreto 104/2011, de 19 de abril, que aprueba los Estatutos de la Agencia de Medio Ambiente y Agua de Andalucía; Decreto 92/2011, de 19 de abril, que aprueba los Estatutos de la Agencia Andaluza del Conocimiento; Decreto 101/2011, de 19 de abril, que aprueba los Estatutos de la Agencia de Servicios Sociales y Dependencia de Andalucía; Decreto 94/2011, de 19 de abril, que aprueba los Estatutos de la Agencia de Obra Pública de la Junta de Andalucía; Decreto 96/2011, de 19 de abril, que aprueba los Estatutos del Servicio Andaluz de Empleo; Decreto 103/2011, de 19 de abril, que aprueba los Estatutos de la Agencia Andaluza de Instituciones Culturales; Decreto 99/2011, de 19 de abril, que aprueba los Estatutos de la Agencia de Gestión Agraria y Pesquera; Decreto 98/2011, de 19 de abril, por el que se aprueban los Estatutos de la Agencia Pública Empresarial Sanitaria Costa del Sol, y se modifican los de otras Agencias Empresariales Sanitarias. Todos ellos, publicados en BOJA n 83 de 29 de abril) y de los diferentes Protocolos de Integración mediante Resoluciones de la Secretaría General para la Administración Pública (todas ellas) de 20 de abril de 2011.

${ }^{2}$ Contestación social que coincidió en el tiempo con unas elecciones sindicales y unas elecciones autonómicas 
que la ley 1/2011 no es una "ley de función pública", sino una ley de carecer estrictamente organizativo, ligada a la consecución de la eficiencia de las estructuras administrativas. Es una ley que culmina un proceso de extinción de determinadas entidades instrumentales y de concentración de otras tantas bajo formas de personificación jurídico-públicas, proceso parejo a otros similares en el común de Administraciones.

Entiéndase que, en la sentencia que se glosa, el Tribunal Constitucional no se ha enfrentado al análisis de una actuación singular y exclusiva de la Comunidad Autónoma Andaluza. El contexto normativo a nivel nacional está conformado, respecto del sector público estatal por la Ley 15/2014, de 16 de septiembre, de racionalización del Sector Público y otras medidas de reforma administrativa ${ }^{3}$ y a nivel local por la Ley 27 /2013, de 27 de diciembre, de racionalización y sostenibilidad de la Administración Local ${ }^{4}$. En el ámbito autonómico, son numerosas las normas que atienden a la finalidad de reestructuración administrativa: entre otros, Ley Foral Navarra 8/2009, de 18 de junio, Decreto-Ley 1/2011, de 30 de septiembre, de Medidas urgentes de régimen económico financiero del sector público empresarial y fundacional de la Comunidad Valenciana, Decreto-Ley 1/2011, de 29 de noviembre, de Medidas urgentes de racionalización del sector público empresarial de Aragón.

Más aún, la reforma de la Administración en un contexto de crisis ha sido principio de actuación a nivel internacional, tanto en la Administración de la Unión Europea $^{5}$ como en los distintos estados de la Unión ${ }^{6}$ y motivo de especial atención de organismos internacionales en su propia referencia al caso español: "Racionalizar las empresas públicas, fundaciones y observatorios públicos: antes de la publicación de la reforma de la

${ }^{3}$ Previamente, Orden HAP5583/2012, de 20 de marzo, por la que se publica el Acuerdo del Consejo de Ministros de 16 de marzo de 2012, por el que se aprueba el plan de reestructuración y racionalización del sector público empresarial y fundacional estatal.

${ }^{4}$ Reformas todas ellas muy comentadas por la doctrina. Entre otros trabajos, cfr. MONTOYA MARTÍN, E. "Reflexiones sobre el sector público instrumental en un contexto de crisis económica: la inaplazable hora de la racionalización". Ponencia presentada en el VII Congreso de profesores de Derecho Administrativo. Tarragona, 2012. Disponible en www.aepda.es/AEPDAAdjunto-250-Ponencia-de-laProfa-Encarnacion.*

5 "La Administración de la Comisión Europea como ejemplo de la reforma de la Administración Pública Europea: análisis en clave constitucional en el contexto de la crisis económica". ELÍAS MÉNDEZ, C. Revista de Derecho Constitucional Europeo, núm.20/2013.

${ }^{6}$ SCHILLACI, A: "Crisis económica, participación y reformas de las Administraciones Públicas"; POLI, T.N: "Las transformaciones de la Administración Pública entre Constitución formal y Constitución 
CORA, se habia dispuesto ya un plan para la reestructuración y la racionalización de las empresas públicas y las fundaciones a todos los niveles de la Administración, incluidas las entidades públicas a escala subnacional. La reforma reitera la necesidad de avanzar en esa racionalización. Igualmente, identifica observatorios públicos territoriales redundantes (muchos de ellos en las CC. AA. y otros en los municipios) y propone la unificación de tales entidades, o su integración dentro del observatorio del Gobierno central pertinente. La reforma de la CORA planea suprimir 90 observatorios de las CC. AA. en áreas como empleo, TIC, turismo, comercio, sanidad y juventud. ${ }^{7 "}$.

Por consiguiente, el objeto de la Ley 1/2011 es la reacción sobre la estructura administrativa andaluza para hacer frente a las exigencias de la crisis económica ${ }^{8}$, aprovechando esta oportunidad para lograr, en lo sucesivo, una mayor eficiencia en su actividad, siempre desde el respeto al marco constitucional y con el objetivo político de conseguir la "vuelta al Derecho Administrativo". Y es que, frente a la acusación de "privatizar" la actuación administrativa y de desplazar a los funcionarios de las funciones de autoridad que les corresponden, lo cierto es que la Ley 1/2011 llevó aparejada la adscripción de funcionarios de carrera a las citadas Agencias para la realización de aquellas funciones que el Estatuto Básico del Empleado Público (EBEP Ley 7/2007, de 12 de abril, art. 9.2 $2^{9}$ les reservaba y que en el escenario anterior a la aprobación de la Ley 1/2011, realizaba personal laboral de aquellas sociedades mercantiles y fundaciones instrumentales. Es bien cierto que este proceso de adscripción de funcionarios no está concluido y que se compagina con el desarrollo transitorio de funciones por el personal laboral que las viniera prestando antes de la entrada en vigor

material"; CORFIATI, F: "Los proyectos de reforma de la Administración y del sector público desde el comienzo de la crisis económica: el apogeo de la austeridad". Todos ellos en Revista de Derecho Constitucional Europeo, núm.22/2014. También, VECCHIO F.'Crisis económica y evolución de la Administración Pública en Europa" Revista de Derecho Constitucional Europeo, num. 23/2015.

7 "Simplificación administrativa y gobernanza multinivel", en el informe "España: de la Reforma de la Administración a la Mejora Continua. Informe de la OCDE sobre gobernanza pública en España", pags. 89 y ss. INAP. OCDE, 2014.

${ }^{8}$ En el Consejo de Política Fiscal y Financiera del 24 de noviembre de 2010 se constató la corrección de las medidas que, en su conjunto, Andalucía había desarrollado, permitiendo augurar el cumplimiento del objetivo de endeudamiento regional autorizado. En nuestro trabajo ORTIZ MALLOL. J. "Una reforma del sector público y de la administración andaluza: la vuelta al derecho administrativo y la reducción del gasto público como principios inspiradores", RAAP 79/2011, ya subrayábamos este enfoque económico.

9 "En todo caso, el ejercicio de las funciones que impliquen la participación directa o indirecta en el ejercicio de las potestades públicas o en la salvaguardia de los intereses generales del Estado y de las Administraciones Públicas corresponden exclusivamente a los funcionarios públicos, en los términos que en la ley de desarrollo de cada Administración Pública se establezca". 
del EBEP ${ }^{10}$, pero ello sólo tiene una lectura: la (excesiva, a nuestra opinión) cautela del Gobierno Andaluz por llevar a sus últimas consecuencias el proceso emprendido con la aprobación del Decreto-ley 5/2010, encuentra tras esta sentencia del Tribunal Constitucional la garantía jurídica de la constitucionalidad de su actuación, por lo que ya nada debe obstar para el completo desarrollo de las consecuencias y premisas de la Ley 1/2011, entre ellas, culminar el proceso de adscripción funcionarial.

Con estos rudimentarios argumentos, propios de una mera introducción al comentario de una sentencia, intentamos dar veracidad a la frase con que comenzamos este artículo. La reforma operada por la Ley $1 / 2011$ no es un mero ejercicio de voluntad política de entre varios posibles. Antes bien, la reordenación que contiene es un ejercicio obligado por la situación económica, ejercicio que fue pieza clave en la respuesta de esta Comunidad Autónoma a la crisis económica sufrida. Deshacer lo que era necesario hacer hubiera tenido, forzosamente, efectos negativos para el común de ciudadanos y ciudadanas andaluces, efectos que hubieran trascendido a una discusión jurídica.

\section{CONTEXTO JURISDICGIONAL}

\section{Precedentes}

Desde una perspectiva estrictamente judicial, la STC 236/2015 pone fin a una dilatada senda de pronunciamientos jurisdiccionales, recaídos tanto ante Juzgados de lo Contencioso-Administrativo, como ante el Tribunal Superior de Justicia de Andalucía - en sus tres Salas de Granada, Málaga y Sevilla- y finalmente, ante el Tribunal Supremo, que se enfrentaron a la impugnación de los Decretos-Leyes 5/2010 y 6/2010, los Decretos aprobatorios de los Estatutos de las Agencias creadas y los protocolos de integración.

\footnotetext{
${ }^{10}$ Es significativo cómo el Real Decreto Legislativo 5/2015, de 30 de octubre, por el que se aprueba el texto refundido de la Ley del Estatuto Básico del Empleado Público, mantiene esta norma de derecho transitorio: "el personal laboral fijo que a la entrada en vigor de la Ley 7/2007, de 12 de abril, estuviere esté desempeñando funciones de personal funcionario, o pasare a desempeñarlos en virtud de pruebas de selección o promoción convocadas antes de dicha fecha, podrá seguir desempeñándolos" (DT 2a). Sin duda, el Legislador nacional del RD 5/2015 (curiosamente, el Partido Popular, el mismo que a través de su Grupo Parlamentario recurrió la Ley andaluza), era sabedor de lo que se traía entre manos y cómo la prestación de los servicios públicos a través de personal laboral debería mantenerse en una transición gradual hasta su completa cobertura por personal funcionario, para evitar una ruptura traumática en su prestación que hubiera perjudicado necesariamente a la parte más débil: los ciudadanos que reciben tales servicios públicos.
} 
Creemos por ende, oportuno centrar el estudio de la STC 236/15 con una previa exposición de lo que ya se había dicho en sede judicial en relación a las disposiciones que se habían dictado al amparo de la Ley impugnada. Y para realizar este repaso, nada mejor que adoptemos la óptica de lo resuelto por el Tribunal Supremo, última instancia jurisdiccional.

En resumen, puede decirse que el Tribunal Supremo ha resuelto una serie de recursos de casación contra Sentencias dictadas por las tres Salas de lo Contenciosoadministrativo del Tribunal Superior de Justicia de Andalucía (Sevilla, Granada y Málaga). En todos los casos los motivos de casación eran sustancial, cuando no literalmente, coincidentes. En dichas sentencias se han desestimado los recursos contra las desestimatorias de los correspondientes recursos contencioso-administrativos y por el contrario se han estimado los recursos contra las sentencias que habían estimado los recursos contencioso-administrativos, con la consecuente anulación de estas sentencias y desestimación de dichos recursos.

Un primer grupo lo constituyen las sentencias dictadas en los recursos contra sentencias de la Sala de lo Contencioso-administrativo de Málaga, entre otras:

- Sentencia de 25 de marzo de 2013, dictada en el recurso de casación 1197/2012, formulado contra la Sentencia de 2 de febrero de 2012, desestimatoria del recurso contencioso-administrativo interpuesto por la vía especial de protección de derechos fundamentales por la Central Sindical Independiente y de Funcionarios (CSI-F), contra el Decreto 92/2011, por el que se aprueban los estatutos de la Agencia Andaluza del Conocimiento.

- Sentencia de 16 de septiembre de 2013, dictada en el recurso de casación $1001 / 2012$, formulado contra la Sentencia de 16 de enero de 2012, desestimatoria del recurso contencioso-administrativo interpuesto por el Sindicato Andaluz de Funcionarios de la Junta de Andalucía, contra el Decreto 101/2011, por el que se aprueban los estatutos de la Agencia de Servicios Sociales y Dependencia de Andalucía.

- Sentencia de 15 de noviembre de 2013, dictada en el recurso de casación 1690/2012, desestimatoria del recurso contencioso-administrativo interpuesto por la vía especial de protección de derechos fundamentales por la Central Sindical Independiente y de Funcionarios (CSI-F), contra el Decreto 101/2011, de 19 de abril, por el que se aprueban los Estatutos de la Agencia de Servicios Sociales y Dependencia de Andalucía.

- Sentencia de 14 de julio de 2014, dictada en el recurso de casación 2086/2013, formulado contra sentencia de 29 de abril de 2013, que desestimaba el recurso contencioso-administrativo interpuesto por la Asociación Al Andalus de Emplea- 
dos Públicos de la Junta de Andalucía y otros contra el Decreto 101/2011, de 19 de abril, por el que se aprueban los estatutos de la Agencia de Servicios Sociales y Dependencia de la Junta de Andalucía.

- Sentencia de 24 de noviembre de 2014, dictada en el recurso de casación 2118/2013, formulado contra sentencia de 22 de abril de 2013, que desestimaba el recurso contencioso-administrativo interpuesto por el Sindicato Andaluz de Funcionario de la Junta de Andalucía contra el Decreto 94/2011, de 19 de abril, por el que se aprueban los estatutos de la Agencia de Obra Pública de la Junta de Andalucía

En el segundo grupo, se encuentran las sentencias dictadas contra Sentencias de las Salas de lo Contencioso-administrativo de Sevilla y Granada, entre las cuales se pueden citar:

- Sentencia de 21 de enero de 2013, dictada en el recurso de casación 6191/2011, formulado contra la sentencia de 2 de noviembre de 2011, que estimaba la petición subsidiaria del recurso contencioso-administrativo interpuesto por la vía especial de protección de derechos fundamentales por la Asociación Al Andalus de Empleados Públicos de la Junta de Andalucía, Asociación Defiendo mi Derecho a la Gestión Pública y otros contra el Decreto 103/2011, de 19 de abril, por el que se aprueban los estatutos de la Agencia Andaluza de Instituciones Culturales.

- Sentencia de 25 de marzo de 2013, dictada en el recurso de casación 1326/2012, formulado contra Sentencia de 20 de febrero de 2012 , estimatoria del recurso contencioso-administrativo interpuesto por la vía especial de protección de derechos fundamentales por Asociación Al Andalus de Empleados Públicos de la Junta de Andalucía, Asociación Defiendo mi Derecho a la Gestión Pública y otros contra el Decreto 92/2011, de 19 de abril, por el que se aprueban los Estatutos de la Agencia Andaluza del Conocimiento.

- Sentencia de 2 de octubre de 2013, dictada en el recurso de casación 1707/2012, formulado contra sentencia dictada el 20 de febrero de 2012, estimatoria del recurso contencioso-administrativo interpuesto por Asociación Al Andalus de Empleados Públicos de la Junta de Andalucía, Asociación Defiendo mi Derecho a la Gestión Pública y otros para la protección de los derechos fundamentales contra el Decreto 96/2011, de 19 de abril, por el que se aprueban los estatutos del Servicio Andaluz de Empleo.

- Sentencia de 4 de octubre de 2013, dictada en el recurso de casación 3213/2012, formulada contra la sentencia dictada el 28 de junio de 2012, que estimaba parcialmente el recurso contencioso-administrativo interpuesto por Asociación Al Andalus de Empleados Públicos de la Junta de Andalucía, Asociación Defiendo mi Derecho a la Gestión Pública contra el Decreto 104/2011, de 19 de abril y, 
Resolución de 20 de abril de 2011 de la Secretaría General para la Administración Pública por el que se aprueban los Estatutos de la Agencia de Medio Ambiente y Agua de Andalucía y el Protocolo de Integración de la Agencia.

- Sentencia de 9 de octubre de 2013, dictada en el recurso de casación 2102/2012, formulada contra la sentencia 19 de abril de 2012 que estimaba parcialmente el recurso contencioso-administrativo interpuesto por la vía especial de protección de derechos fundamentales por Central Sindical Independiente de Funcionarios (CSI-F) contra el Decreto 104/2011 de 19 de abril, por el que se aprueban los Estatutos de la Agencia de Medio Ambiente y Agua de Andalucía.

- Sentencia de 15 de noviembre de 2013, dictada en el recurso 381/2012, formulado contra la sentencia de 15 de diciembre de 2011, que estimaba parcialmente el recurso contencioso-administrativo interpuesto Unión Sindical Obrera (USO) para la protección de los derechos fundamentales contra el Decreto 104 y 105/2011 de 19 de abril, por los que se aprobaban los Estatutos de la Agencia de Medio Ambiente y Agua de Andalucía se establece la estructura orgánica de la Consejería de Medio Ambiente de la Junta de Andalucía.

- Sentencia de 20 de diciembre de 2013, dictada en el recurso de casación $3425 / 2012$, formulado contra sentencia de 24 de julio de 2012, que estimaba parcialmente el recurso contencioso-administrativo interpuesto por Asociación $\mathrm{Al}$ Andalus de Empleados Públicos de la Junta de Andalucía, Asociación Defiendo mi Derecho a la Gestión Pública y otros contra el Decreto 96/2011, de 19 de abril, por el que se aprueban los estatutos del Servicio Andaluz de Empleo.

- Sentencia de 30 de diciembre de 2013, dictada en el recurso de casación $3633 / 2012$, formulado contra la sentencia de 10 de julio de 2012, que estimaba parcialmente el recurso contencioso-administrativo interpuesto por la Central Sindical Independiente y de Funcionarios (CSI-F) contra el Decreto 96/2011, de 19 de abril, por el que se aprueban los estatutos del Servicio Andaluz de Empleo.

- Sentencia de 30 de diciembre de 2013, dictada en el recurso de casación 3355/2012, formulado contra la sentencia de 18 de junio de 2012, que estimaba parcialmente el recurso contencioso-administrativo interpuesto por Sindicato Andaluz de Funcionarios de la Junta de Andalucía contra el Decreto 92/2011, se 19 de abril, por el que se aprueban los estatutos de la Agencia Andaluza del Conocimiento.

- Sentencia de 27 de enero de 2014, dictada en el recurso de casación 3740/2012, formulado contra Sentencia de 13 de septiembre de 2012, que estimaba parcialmente el recurso contencioso-administrativo interpuesto por la Asociación Al Andalus de Empleados Públicos de la Junta de Andalucía, Asociación Defiendo mi Derecho a la Gestión Pública y otros por el cauce del art. 114 y ss. LJCA contra 
el Decreto 104/2011, de 19 de abril, por el que se aprueban los Estatutos de la Agencia de Medio Ambiente y Agua de Andalucía.

- Sentencia de 29 de enero de 2014, dictada en el recurso de casación 3818/2012, formulado contra Sentencia de 13 de septiembre de 2012, que estimaba parcialmente el recurso contencioso-administrativo interpuesto por Asociación Sindical de Ingenieros de Caminos, Canales y Puertos al Servicio de la Administraciones Publicas (ASICAD) y Asociación General del Cuerpo de Ingenieros de Caminos, Canales y Puertos del Estado (AICCPE) contra el Decreto 104/2011, de 19 de abril, por el que se aprueban los Estatutos de la Agencia de Medio Ambiente y Agua de Andalucía.

- Sentencia de 11 de febrero de 2014, dictada en el recurso de casación 3998/2012, formulado contra Sentencia de 30 de abril de 2012, que estimaba la petición subsidiaria del recurso contencioso-administrativo interpuesto por Asociación $\mathrm{Al} \mathrm{An}$ dalus de Empleados Públicos de la Junta de Andalucía, Asociación Defiendo mi Derecho a la Gestión Pública y otros contra el Decreto 99/2011, de 19 de abril, por el que se aprueban los Estatutos de la Agencia de Gestión Agraria y Pesquera de Andalucía.

- Sentencia de 24 de marzo de 2014, dictada en el recurso de casación 739/2013, formulado contra sentencia de 19 de noviembre de 2012, que estimaba parcialmente el recurso contencioso-administrativo interpuesto por el Sindicato Andaluz de Funcionarios de la Junta de Andalucía contra la resolución de 20 de abril de 2011 por la que se aprueba el Protocolo de Integración del personal en la Agencia de Conocimiento de la Junta de Andalucía.

- Sentencia de 26 de marzo de 2014, dictada en el recurso de casación 480/2013, formulado contra Sentencia de 16 de enero de 2013, que estimaba parcialmente el recurso contencioso-administrativo interpuesto por Asociación Al Andalus de Empleados Públicos de la Junta de Andalucía, Asociación Defiendo mi Derecho a la Gestión Pública y otros contra el Decreto 92/2011, de 19 de abril, por el que se aprueban los Estatutos de la Agencia Andaluza del Conocimiento.

- Sentencia de 8 de abril de 2014, dictada en el recurso de casación 1006/2013, formulado contra la sentencia de 29 de octubre de 2012, que estimaba parcialmente el recurso contencioso-administrativo interpuesto por el Sindicato Andaluz de Funcionarios de la Junta de Andalucía contra la Resolución de 20 de abril de 2011, por la que se aprueba el Protocolo de integración del personal en la Agencia de Servicios Sociales y Dependencia de Andalucía.

Como se puede observar, el Tribunal Supremo ha ratificado la posición mantenida por la Sala de Málaga del Tribunal Superior de Justicia (favorable a la legalidad de las disposiciones de aplicación de la Ley de Reordenación) y ha corregido la 
postura desarrollada por las Salas de Granada y Sevilla ${ }^{11}$, contrarias a las disposiciones de desarrollo de tal ley. El Tribunal Constitucional, confirmando la constitucionalidad de la Ley 1/2011, se alinea con el Tribunal Supremo y la Sala de Málaga del Tribunal Superior de Justicia.

La postura del Supremo -mantenida en el común de pronunciamientos, con usuales remisiones a sentencias precedentes- se puede resumir de la siguiente forma. Habida cuenta que la discusión se centraba en determinar si el proceso de reordenación suponía la vulneración del derecho de acceso a las funciones públicas conforme a los principios de igualdad, mérito y capacidad, se constataba que el personal laboral de las mercantiles y fundaciones de mano pública objeto de la reordenación no cambió su régimen jurídico como tampoco cambió la titularidad pública de la Administración matriz de las entidades empleadoras, ni el objeto de la actividad de cada cual. El Tribunal Supremo señala que en el común de los casos, se dio el supuesto de hecho de la sucesión de empresas regulada en el art. 44 del Estatuto de los Trabajadores. De otro lado, sostuvo que este proceso de reordenación ya disponía que ese personal laboral solamente pudiera adquirir la condición de funcionario o de personal laboral de la Junta de Andalucía si superaba los correspondientes procesos selectivos.

Tales hechos constatados por el Tribunal Supremo "impiden apreciar un acceso al empleo público que merezca ser calificado de gratuito, ilegal o injustificadamente discriminatorio. $\mathcal{N}_{0}$ es ilegal porque, por un lado, está amparado en lo que establece la Ley 1/2011 y, por otro, es coherente con lo establecido en el art. 44 del Estatuto de los Trabajadores. Tampoco es gratuito, arbitrario o injustificadamente discriminatorio, porque pretende cohonestar la nueva configuración del sector público de Andalucía, dispuesta por el legislador autonómico, con la estabilidad en el empleo de quienes ya la tenían como personal laboral en las empresas públicas que resultan extinguidas en esa reordenación del sector público legalmente establecida; y porque la integración no supone ningún plus

${ }^{11}$ En la STS de 9 de abril de 2014 -de la cual se extraen el resto de citas- se afirmaba que: "Añadiremos a lo anterior que, si la Sala de Sevilla no dudó de la constitucionalidad de la Ley 1/2011, lo que hubo de hacer es desestimar el recurso contencioso-administrativo pues, limitándose el Decreto 104/2011 al estricto cumplimiento de lo establecido por ella y siendo constitucional el Decreto, tampoco podía infringir los artículos 14 y 23.2 de la Constitución". Más allá de la evidente defensa de la independencia judicial, resulta complicado explicar fuera del estricto discurso jurídico, cómo un mismo Tribunal no fue capaz de coordinar la posición de sus distintas Salas, ofreciendo un resultado, cuanto menos, llamativo: los Estatutos que se impugnaban recibían el respaldo o la crítica del Tribunal Superior de Justicia en función de la Sala a la que correspondía enjuiciar por razón de competencia material. 
adicional al status laboral que antes poseía el personal integrado, al quedar circunscrita, como ya se ha señalado, a la Agencia que ha sucedido en su actividad a la empresa pública suprimida y no permitir a dicho personal pasar por vías excepcionales a la Administración General del Junta de Andalucía”.

En consecuencia y por lo que respecta al derecho a la promoción profesional, el Supremo, acogiendo el parecer del Ministerio Fiscal, ha sostenido que "la integración dispuesta en estricto cumplimiento de la disposición adicional cuarta de la Ley 1/2011, no produce por si ninguna lesión concreta y actual de ese derecho a la promoción profesional de los actores en la instancia. No la produce porque no se integra en el sector público a quienes no lo estuvieran y a y, tampoco, implica una actuación dirigida a sustraer a funcionarios o personal laboral de otros entes públicos de la Junta de Andalucía puestos de trabajo determinados a cuya provisión, de otro modo, hubieran podido aspirar".

Cuanto la postura del Tribunal Supremo estaba ya suficientemente asentada, el propio Tribunal Constitucional dictó, días antes de emitir la sentencia que nos ocupa, la Sentencia 230/2015, de 5 de noviembre, que resolvía la impugnación contra la disposición adicional cuarta y los arts. 1, apartados 9 y 12, 3 a 12, 18, 19 y 22 a 24 del Decreto-ley de Andalucía 5/2010, de 27 de julio, por el que se aprueban medidas urgentes en materia de reordenación del sector público.

Los motivos de impugnación eran los siguientes: en primer lugar, que en su tramitación, el Decreto-ley 5/2010 no habría respetado la exigencia de negociación previa con los representantes de los trabajadores; en segundo lugar la vulneración de la reserva de actuación a los funcionarios (relativo al ejercicio de las potestades públicas y la salvaguarda de los intereses generales). En tercer lugar se alegaba la vulneración del contenido esencial de los arts. 14 y 23.2 CE, en lo relativo al acceso en condiciones de igualdad a la función pública, en virtud del contenido que se da a las fórmulas de reordenación y reasignación del personal al servicio de la administración pública autonómica. Por último, la no concurrencia del presupuesto habilitante de todo decreto ley como es su condición de extrema y urgente necesidad.

El Constitucional tiene en cuenta que el Decreto-ley 5/2010, después de ser convalidado por la Diputación permanente del Parlamento de Andalucía, fue modificado por el Decreto-ley 6/2010, de 23 de noviembre, de medidas complementarias del mismo. Esta reforma, "respondía a la necesidad de aplicar las medidas derivadas de Decreto-ley con el mayor grado de consenso posible, dada su repercusión, de modo que establece innovaciones surgidas del diálogo social permanente con las organizaciones sindicales Unión General de Trabajadores de Andalucía y Comisiones Obreras de Andalucía y del diálogo habido en el seno de la mesa general de negociación del empleado público de la Administración de la Junta de Andalucía". 
El Decreto-Ley 6/2010, fue tramitado como proyecto de Ley por el procedimiento de urgencia y aprobado finalmente como Ley $1 / 2011$, de 17 de febrero, de reordenación del sector público de Andalucía. En el mismo sentido que lo hiciera el Decreto-ley 6/2010, la disposición derogatoria única de la Ley 1/2011 dispone que "quedan sin efecto todos los preceptos contenidos en otras normas y cuyo tenor se reproduce en la presente Ley, así como cuantas normas contradigan o se opongan a lo dispuesto en la misma". Por lo que la totalidad de preceptos impugnados en este recurso de inconstitucionalidad habían, a tal fecha, sido derogados o sustituidos, en primer término, por el Decreto-ley 6/2010 y seguidamente por la Ley 1/2011. Lo cual supuso que el Constitucional acordara declarar la extinción del recurso por desaparición sobrevenida del objeto respecto de los arts. 3 a 12, 18, 19 y 22 a 24 del Decreto-ley de Andalucía 5/2010.

Sin embargo, el Constitucional consideró necesario el análisis de la concurrencia del presupuesto habilitante de todo decreto ley como es su condición de extrema y urgente necesidad. El Decreto Ley 5/2010 fundaba la situación de urgencia en el cumplimiento de los objetivos de déficit contenidos en el Acuerdo Marco con las Comunidades Autónomas y Ciudades con Estatuto de Autonomía sobre Sostenibilidad de las Finanzas Públicas para el periodo 2010-2013, adoptado en el seno del Consejo de Política Fiscal y Financiera el 22 de marzo de 2010, a raíz de la Actualización del Plan de Estabilidad y Crecimiento 2010-2013. En este contexto, a tenor del Constitucional, la disposición adicional cuarta "al referirse a la reestructuración del sector público andaluzy, en particular, a la supresión o extinción de centros directivos de consejerías y entidades instrumentales, conecta directamente con los objetivos de contención del déficit público, que son los que justifican - según la exposición de motivos y el trámite de convalidación, y por referencia a los acuerdos del Consejo de Política Fiscal y Financiera de 15 de junio de 2010 - la aprobación del Decreto-ley".

Sin embargo, "el resto de medidas puede de algún modo conectarse con la reforma del sector público, pero no tienen una relación inmediata y directa con el objetivo de reducción del déficit público. No existiendo, por tanto, una justificación especifica relativa a las medidas impugnadas, ni pudiendo entenderse implícitamente justificada la concurrencia del presupuesto habilitante por subsunción en la justificación genérica expuesta", se decretó la inconstitucionalidad del art. 1, apartados 9 y 12 aunque -claro está- inconstitucionalidad sin repercusión jurídica alguna, habida cuenta la vigencia de la Ley $1 / 2011$.

\section{Secuelas de la Sentencia $236 / 15$}

Hasta este punto, se han expuesto los pronunciamientos que precedieron la Sentencia que se glosa. El escaso transcurso de tiempo entre su publicación y la redacción de este comentario, ha impedido la recepción de la misma en las instancias 
jurisdiccionales con la excepción -a día de la entrega de este trabajo y que conozcamos- de sendas sentencias del Tribunal Superior de Justicia de Andalucía, Sala de Sevilla, de 18 de febrero de 2016. Una y otra recaen con ocasión de la impugnación del Decreto 122/2014, de 26 de agosto, por el que se aprueban los Estatutos de la Agencia de Innovación y desarrollo de Andalucía y el Decreto 8/2014, de 21 de enero, por el que se modifican los Estatutos de la Agencia Andaluza de la Energía. En ambas sentencias, el Tribunal Superior de Justicia asume la constitucionalidad de la Ley 1/2011 y en consecuencia, dice: que “(...) el planteamiento del resto de los motivos de impugnación del Decreto resultaría acertado, si no fuera porque, es de nuevo la Ley de Reordenación del Sector Público Andaluz la que ha cambiado el régimen jurídico de la Agencia (...) De ahí, la seria preocupación de la Asociación sobre que sea este personal laboral el que lleve acabo el ejercicio de potestades administrativas reservadas constitucional y legalmente a los funcionarios públicos. Preocupación que comparte este Tribunal, sin embargo, el Legislador andaluz lo ha solventado al menos formalmente en el art. 69 apartado 2 y 3 de la Ley $1 / 2011$ y disposición adicional quinta y sexta, que se reproduce a su vez el art. 34 de Decreto (...) Por tanto, el Decreto no atribuye potestades administrativas al personal laboral, sino que respeta la reserva de ese ejercicio a los funcionarios públicos que se adscriban, lo que la Ley difiere a la relación de puestos de trabajo de la Consejería de la que dependa (y no a los Estatutos) (...) Tampoco apreciamos vulneración de los arts. 14 y 81 del Estatuto Básico, porque el régimen jurídico de los funcionarios adscritos a la Agencia no se ve alterado (art. 34 del Decreto), tampoco en su inmovilidad ya que la adscripción sería voluntaria y se instrumenta a través de las correspondientes relaciones de puestos de trabajo de la Consejería de la que dependen, a quien las funciones se ejerzan bajo la dirección funcional de la Agencia cuyo titular aunque personal de confianza, es funcionario al ser nombrado por el Consejo de Gobierno según prevé la disposición adicional quinta y sexta de la Ley 1/2011 y el propio Decreto".

Resulta, como consecuencia de la sentencia del Tribunal Constitucional que estamos glosando, un obligado cambio de rumbo de 180 grados en la postura de esta Sala respecto de la que impuso al enjuiciar los estatutos de las agencias aprobados al amparo de la Ley $1 / 2011$.

En una declaración que podría recordar al aforismo "vencida, que no convencida", dice la Sala de Sevilla :"Resulta obvio que por razones de oportunidad, se ha optado en nuestra Comunidad Autónoma por una Administración Instrumental en detrimento de la Administración Central y de los funcionarios públicos que la integran, que están viendo mermadas sus funciones y carrera profesional, pero sería la Ley a la que se adapta el Decreto y que establece el régimen jurídico e las Agencias y de su personal a al que se podría imputar las vulneraciones constitucionales denunciada, sin embargo el Tribunal Constitucional en sentencia de 19 de noviembre de 2015 ha desestimado el recurso de inconstitucionales que pendía contra aquella $n^{\circ}$ $2733 / 2011$ por lo que no existe reproche que hace la actora y los dos votos particulares de la sentencia del Pleno referida". 
En cualquier caso, según decimos, la Sala se alinea con la explícita (y terminante) declaración de constitucionalidad de la Ley 1/2011 y en esta misma coherencia, contiene la sentencia un importantísimo párrafo: "ahora bien, no basta con que los actos finales sean dictados y firmados por el Presidente de la Agencia, que en ese caso correspondería al Viceconsejero u órganos directivos que tienen expresamente atribuida la potestad administrativa, pues esa toma de decisión debe ir precedida de la instrucción de un procedimiento que incumbe exclusivamente a los funcionarios. Así lo hemos afirmado en numerosas sentencias respecto a encomiendas de gestión anuladas por esta Sala y confirmadas por el Tribunal Supremo,"que no se pueden llevar a cabo por personal laboral, actuaciones of funciones de dación de fe pública y gestión de registros administrativos, asesoramiento legal preceptivo, control y fiscalización interna de la gestión económica financiera y presupuestaria, de evaluación, control, autorizatorias de vigilancias e inspección, propuesta de resolución etc., de naturaleza indubitadamente administrativa"; para concluir en un postrer considerando que "se deberá cumplir la previsión normativa de elaboración de la relación de puestos de trabajo por parte de la Consejería de la que depende la Agencia, no bastando adscribir unos cuantos funcionarios interinos, que resultan a todas luces insuficientes dadas las numerosas potestades administrativas que tiene encomendada la Agencia".

Según decimos, es un muy importante pronunciamiento, en tanto que aclara el esquema de funcionamiento impuesto por la Ley 1/2011, más allá del juego de la disposición transitoria $2^{a}$ del TREBEP, ya reproducida: el hecho de que se reconozca a la Agencia Pública el ejercicio de potestades no evita la necesaria intervención de funcionario público en aquellos trámites que le están reservados. Esta era, precisamente, la idea perseguida por la Ley de Reordenación del Sector Público, por lo que tal declaración judicial participa del espíritu material (y no puramente formal) de tal norma. Mas la mayor trascendencia de lo que dice la esta sentencia aparece al enumerar estas funciones reservadas a personal funcionario, siendo tal enumeración precisamente- una de las carencias del ordenamiento jurídico andaluz a día de hoy ${ }^{12}$. Enumeración que es implícitamente requerida por la propia Ley 1/2011.

Para finalizar y siendo congruente con todo lo dicho, el Tribunal andaluz admite el recurso en cuanto que se modifica el art. 7 del Decreto 59/2005 sobre el control administrativo a través de VIASA como medio que no podrá implicar la atribución de potestades, funciones o facultades sujetas al Derecho Administrativo, en cuanto que, dada la naturaleza mercantil de aquella, se vulnera la prohibición de la

\footnotetext{
${ }^{12}$ Entre otros tantos estudios sobre este particular, cfr. CANTERO MARTÍNEZ, J. "Funcionarios y laborales (a propósito del ejercicio de potestades públicas en la Administración y de la reserva funcionarial", ponencia presentada en el VI Congreso sobre Gestión de Recursos Humanos en la Administración Pública, Vitoria 2010. wrwre.vitoria-gasteiz.org/wb021/http/contenidosEstaticos/.../32978.pdf
} 
Ley 9/2007 de Administración de la Junta de Andalucía, de atribución de funciones que impliquen el ejercicio de potestades públicas a sociedades mercantiles y la reserva funcionarial del art. 9.2 EBEP.

\section{LA SENTENCIA}

\section{Motivos del recurso y posicionamiento de las partes}

El recurso de inconstitucionalidad se dirige contra la Ley $1 / 2011$ en su totalidad, por el vaciamiento de funciones de los servicios centrales y periféricos de la Administración andaluza (art. 133.2 del Estatuto de Autonomía para Andalucía: EAAnd) pero también, en particular, contra los arts. 1.1, 1.2.9, 1.2.10, 1.2.12, 3, 4, 5, 6, $7,8,9,10,11,12,18,19,20,21,22,23$ y 24 , las disposiciones adicionales cuarta y sexta y la disposición derogatoria única, por considerarlos contrarios a los arts. 9.3, 14, 23.2, 53.1, 103.1 y 3 y 149.1.18 CE y 33.1, 76.1 y 2 y 133.2 EAAnd.

De una forma esquemática, los motivos de impugnación, son los siguientes:

a) Los Diputados recurrentes señalaban que la Ley impugnada permite desarrollar la gestión ordinaria de las actividades administrativas desde una "Administración paralela" con la atribución a las "macroagencias" de potestades públicas y gracias a un trasvase masivo de personal desde los servicios centrales y periféricos de las Consejerías hasta esas entidades instrumentales, a través de una adscripción funcional forzosa. En suma, acusaban a la Ley de instaurar un modelo de gestión administrativa con las ventajas del Derecho privado propio de las sociedades mercantiles y las fundaciones (especialmente en lo que se refiere al régimen de contratación y despido de su personal) y los beneficios de las potestades y prerrogativas del Derecho público.

b) Los recurrentes alegaban, en segundo lugar, que el art. 1.1 de la Ley impugnada contiene una prelación de principios de actuación general de la Administración de la Junta de Andalucía que resulta contraria al art. 133.1 EAAnd.

c) En tercer lugar, los Diputados recurrentes argumentaban que la ley recurrida vulnera la reserva funcionarial del art. 9.2 EBEP al dar una nueva redacción al art. 69.1 de la Ley 9/2007, que habilita para atribuir potestades administrativas a agencias públicas empresariales cuyo personal se regirá por el derecho privado y que constituye un fraude al art. 133.2 EAA la solución ideada por el legislador autonómico de recurrir a funcionarios adscritos

d) En cuarto lugar, los recurrentes aducían que la Ley impugnada afecta al carácter básico de las condiciones de movilidad de los funcionarios al instaurar un régimen de dependencia funcional que implica para funcionarios de carrera, una movilidad forzosa del puesto de trabajo, pues bajo la apariencia de mantenimiento en el 
mismo puesto del que se sigue dependiendo orgánicamente existe, en realidad, un traslado encubierto que permite cambiar sus condiciones laborales a través del decreto que apruebe los estatutos de cada agencia, sin respetar las condiciones que se tuvieran en el puesto de origen ni los demás derechos que les reconoce el art. 81.2 EBEP.

e) En quinto lugar, los recurrentes sostenían que, en cuanto al estatuto del personal de las agencias, la Ley impugnada obvia la preferencia constitucional por el régimen funcionarial por cuanto introduce modelos basados en el régimen de derecho privado para su personal.

f) Finalmente, los recurrentes imputaban a varios preceptos de la Ley 1/2011 la lesión del contenido esencial de los derechos fundamentales reconocidos en los arts. 14 y $23.2 \mathrm{CE}$, dado que concurren a la integración de personal en condiciones similares tanto el procedente de agencias administrativas preexistentes como el procedente de entidades privadas de mano pública, al tiempo que extiende este trato a funcionarios y personal laboral de la Junta de Andalucía.

En suma, una enmienda a la totalidad desde un postulado general: la vulneración de la Constitución por el mero hecho de crear un conjunto de agencias públicas a las que se atribuyen el ejercicio de potestades administrativas. De ahí se extrae un discurso de quebrantamiento de la reserva funcionarial del ejercicio de las potestades públicas y por consiguiente, el quebranto del status funcionarial. Todo ello, en connivencia con las acusaciones públicas de creación de una administración paralela de personal laboral supuestamente adepto al partido gobernante.

Oponiéndose a tales argumentos se presentaron escritos por la Letrada de la Junta de Andalucía y por el Letrado del Parlamento Andaluz, en defensa de la constitucionalidad de la ley.

La Letrada de la Junta de Andalucía ${ }^{13}$ sostuvo que la preferencia por la gestión directa no excluye la gestión indirecta ni que la gestión ordinaria directa pueda realizarse a través de entes instrumentales, no pudiendo negarse las competencias propias de autoorganización de la Junta de Andalucía (art. 47.1.1 EAAnd). En relación a la reserva funcionarial, explicó cómo los recurrentes dan un indebido salto cualita-

${ }^{13}$ En concreto, la Sra. CARRETERO ESPINOSA DE LOS MONTEROS. C. es autora de un interesante artículo con clara conexión sobre la materia: "El papel del funcionario y del laboral en el nuevo diseño de la Administración Pública" Aranzadi Doctrinal, núm. 8/2011 
tivo al afirmar que "solo aquellas entidades de derecho público que cuenten con personal funcionario podrán tener atribuidas potestades administrativas" y al considerar que "contar con" equivale necesariamente a la dependencia orgánica del funcionario de la agencia o entidad en cuestión.

Contestando a los argumentos del recurso sobre la carrera funcionarial, la Letrada señalaba que los recurrentes no explican de dónde viene la idea de traslados forzosos que abrogan los procedimientos de promoción profesional establecidos en el EBEP, cuando - precisamente- el art. 69.3 de la Ley 9/2007 remite a las relaciones de puestos de trabajo que se configuren en el futuro y a los decretos por los que se aprueben los estatutos de las agencias, pero sin que en ningún momento se imponga en la norma movilidad forzosa alguna y sin que tampoco se prevea ningún procedimiento de traslados.

La Letrada destacó que se pretende una reorganización administrativa, que afecta al personal al servicio del sector público, pero no en su acceso al empleo público y que en modo alguno debe ser cuestionado que la Junta de Andalucía, en virtud de sus potestades de autoorganización, pueda reorganizar su administración institucional y reducir el número de sus entes. Lo que se discute son las consecuencias en el ámbito del empleo público, siendo aquí donde comienza la confusión de términos. Y es que, indicaba la Letrada, no es lo mismo acceso al empleo público que modificación del régimen de prestación de la relación de servicio por los empleados públicos, quienes no pierden su condición por el hecho de que haya una reordenación administrativa. Y subraya que es cuestión distinta la de quienes, en virtud de un fenómeno de sucesión empresarial ex art. 44 de la Ley del estatuto de los trabajadores, pasan a prestar sus servicios en otra empresa distinta: este grupo de trabajadores no adquiere por ello la condición de empleados públicos conforme a los principios de mérito y capacidad.

Por su parte, sobre el fondo del asunto, el Letrado del Parlamento señaló que las afirmaciones que realizan los recurrentes para justificar el motivo de inconstitucionalidad no satisfacen la carga de la necesaria fundamentación, pues se alega que el supuesto "vaciamiento de funciones de los servicios centrales y periféricos de la Administración andaluza" se produce mediante tres instrumentos: la creación de ocho "macroagencias", la atribución a las mismas de potestades públicas o administrativas, y el trasvase masivo de personal hacia esas entidades instrumentales. Así pues, sería la suma de esos tres instrumentos lo que haría que la Ley 1/2011 fuera inconstitucional. Sin embargo, sostiene el Letrado, ninguno de los tres instrumentos, ni su suma, guarda conexión alguna a la hora de determinar el supuesto vaciamiento de funciones con los preceptos de la Ley $1 / 2011$. 
El Letrado del Parlamento alega, que, con arreglo a los arts. 133.3 y 158 EAAnd, los entes instrumentales son Administración de la Comunidad Autónoma de Andalucía pueden ejecutar las funciones propias de su competencia con plena normalidad y carácter ordinario, de modo que decae inmediatamente toda la argumentación de los recurrentes en tal sentido. Tras recordar la doctrina del Tribunal Constitucional sobre el muy amplio margen de actuación con que cuentan las Administraciones públicas en ejercicio de su potestad de organización a la hora de consolidar, modificar o completar sus estructuras, el Letrado niega que la entidad de las funciones y actividades que se atribuyen a los entes instrumentales a que se refiere la Ley 1/2011 suponga, no ya un "vaciamiento de funciones" de la "Administración de la Funta de Andalucía stricto sensu", sino que -afirma- ésta continúa desarrollando el grueso de las funciones materialmente administrativas de la Junta de Andalucía. En suma, señala que la finalidad de la ley es llevar a cabo una reordenación o restructuración del sector público andaluz, para conseguir, en lo posible, una simplificación y una racionalización de la estructura organizativa.

En su escrito, el Letrado destaca la densidad normativa que la Ley 9/2007 dedica al régimen de actuación de las agencias públicas empresariales, y que su actuación vendrá determinada en todo caso por lo que dispongan la Ley 9/2007, sus respectivas leyes de creación y sus estatutos, además de otras normas que les puedan resultar de aplicación. Y respecto al controvertido inciso "podrá llevarlas a cabo" del art. 69.3 de la Ley 9/2007 en la redacción dada por el art. 1.2.9 de la Ley 1/2011, señala que las funciones podrán ser ejercidas, bien por el personal funcionario perteneciente a la Consejería, bien por el personal funcionario perteneciente a la agencia administrativa a la que esté adscrita la Consejería.

El Letrado del Parlamento de Andalucía rechaza la impugnación relativa a la vulneración de las condiciones básicas de movilidad de los funcionarios. Antes bien, explica cómo, mediante la adscripción de funcionarios, se atribuirá a determinados puestos de trabajo ya existentes en la estructura orgánica, nuevas funciones precisas para que las agencias públicas empresariales puedan desarrollar sus competencias y potestades. La única novedad será el dato de quién es la entidad titular de las competencias a las que se refieren las funciones que se ejercen, la agencia pública empresarial, porque materialmente las funciones coincidirán exactamente con las que venían desempeñando por las entidades instrumentales reordenadas. El personal afectado por esa modificación continuará dependiendo orgánicamente de su Consejería o agencia administrativa, pero funcionalmente de la correspondiente agencia pública empresarial, lo cual constituye una opción organizativa plenamente legítima que respeta el art. 9.2 EBEP, en consonancia con la jurisprudencia constitucional. 
Finalmente, el Letrado del Parlamento rechaza que se produzca vulneración del derecho o principio de igualdad entre diversas parejas de grupos o colectivos de empleados públicos. Para el Letrado, todas las medidas incluidas en la ley tienen una justificación objetiva y razonable, que atiende a la excepcionalidad del proceso de profunda restructuración del sector público andaluz que se adopta y que los recurrentes no discuten.

\section{Posición del Tribunal Constitucional en relación con los distintos motivos del recurso}

Tras el análisis de determinadas cuestiones procesales -en las que no nos detenemos por ser de orden secundario al motivo principal de este comentario-, el Tribunal Constitucional entra en el análisis del fondo del recurso de inconstitucionalidad analizando el pretendido vaciamiento de funciones de los servicios centrales y periféricos de la Administración al posibilitar la ley recurrida desarrollar la gestión ordinaria de las actividades administrativas desde una "Administración paralela".

Ello obliga al Tribunal a la exégesis del art 133.2 EAAnd, que dice: "La Administración de la Junta de Andalucía desarrollará la gestión ordinaria de sus actividades a través de sus servicios centrales y periféricos". Según el Constitucional, este precepto requiere de una interpretación sistemática en relación con el art. 158 y el 133.3: de entrada, cabe afirmar que el Estatuto de Autonomía parte una concepción de Administración autonómica integrada tanto por la "Administración de la funta de Andalucía" como por sus entes instrumentales, de tal modo que no cabe limitar la potestad de autoorganización mediante la creación de entidades instrumentales o a la atribución de funciones a dichas entidades. No contiene el art. 133.2 EAAnd un límite en forma de naturaleza o el quantum de funciones cuya realización tenga que reservarse la Administración de la Junta de Andalucía y no pueda encomendar a sus entidades instrumentales. Ello determina la desestimación del primer motivo de inconstitucionalidad alegado por los recurrentes.

Ligada al anterior, aparece la discusión acerca de si la ley recurrida altera la prelación de principios de actuación de la Administración de la Junta de Andalucía fijada en el art. 133.1 EAAnd. Recordamos que el art. 1.1 de la Ley de Reordenación establece que: "Los ejes de la reordenación o reestructuración, presente o futura, del Sector Público de Andalucía serán la atención a la ciudadanía, el interés general y la calidad de los servicios públicos. En base a ello, los principios de simplificación y racionalización de la estructura organizativa estarán supeditados a los mismos, y a la consecución del objetivo de garantizar los derechos e intereses de los ciudadanos, actuando en beneficio de estos y del interés general.", frente a lo que ordena el art. 133.1: "La Administración de la Junta de Andalucía sirve con objetividad al 
interés general y actúa de acuerdo con los principios de eficacia, eficiencia, racionalidad organizativa, jerarquía, simplificación de procedimientos, desconcentración, coordinación, cooperación, imparcialidad, transparencia, lealtad institucional, buena fe, protección de la confianza legítima, no discriminación y proximidad a los ciudadanos, con sujeción a la Constitución, al Estatuto y al resto del ordenamiento jurídico."

Tras sentar el Tribunal que "del precepto estatutario no se deduce una obligación de la Administración autonómica o de los poderes públicos andaluces de realizar todos y cada uno de los principios al mismo tiempo y con la misma intensidad,", vuelve a recordar la competencia exclusiva de la Comunidad Autónoma sobre su organización y la estructura de sus instituciones de gobierno, por lo que se afirma la libertad del Legislador andaluz al acometer la reordenación de su sector público para otorgar un valor informante superior a determinados principios — a los que califica de "ejes de la reordenación o reestructuración, presente o futura, del Sector Público de Andalucía" - como son la atención a la ciudadanía, el interés general y la calidad de los servicios públicos. Con ello, también se desestima este segundo motivo de impugnación.

En tercer lugar, los Diputados recurrentes argumentan que las modificaciones que el art. 1.2.9 de la Ley 1/2011 introduce en el art. 69 de la Ley 9/2007, de 22 de octubre, de la Administración de la Junta de Andalucía (LAJA) afectan al carácter básico de las funciones reservadas a los funcionarios ex art. 9.2 $\mathrm{EBEP}^{14}$. El Tribunal Constitucional despacha la afirmación de los recurrentes de que este precepto vulnera los arts. 76.1 y 76.2 EAAnd, (que establecen las competencias andaluzas sobre fun-

${ }^{14} \mathrm{El}$ nuevo art. 69 LAJA se pronuncia en los siguientes términos:

"Artículo 69. Régimen jurídico y ejercicio de potestades administrativas

1. Las agencias públicas empresariales a que hace referencia la letra a del apartado 1 del artículo 68 de esta Ley se rigen por el Derecho Privado, excepto en las cuestiones relacionadas con la formación de la voluntad de sus órganos y con el ejercicio de las potestades administrativas que tengan atribuidas y en los aspectos específicamente regulados en esta Ley, en sus estatutos, en la Ley General de la Hacienda Pública de la Junta de Andalucía y demás disposiciones de general aplicación.

Las agencias públicas empresariales a que hace referencia la letra $b$ del apartado 1 del artículo 68 de esta Ley se rigen por el Derecho Administrativo en las cuestiones relacionadas con la formación de la voluntad de sus órganos y con el ejercicio de las potestades administrativas que tengan atribuidas y en los aspectos especificamente regulados en esta Ley, en sus estatutos, en la Ley General de la Hacienda Pública de la Funta de Andalucía y demás disposiciones de general aplicación. En los restantes aspectos se regirán por el Derecho Administrativo o por el Derecho Privado según su particular gestión empresarial asi lo requiera.

2. Las agencias públicas empresariales ejercerán únicamente las potestades administrativas que expresamente se les atribuyan y solo pueden ser ejercidas por aquellos órganos a los que en los estatutos se les asigne expresamente esta facultad. No obstante, a los efectos de esta Ley, los órganos de las agencias públicas empresariales no son asimilables en cuanto a su rango administrativo al de los órganos de la Administración de la funta de Andalucía, salvo las excepciones que, a determinados efectos, se fijen, en cada caso, en sus estatutos. 
ción pública) de manera terminante: "no puede ser admitida, pues tal afirmación no viene acompañada de argumentación alguna que permita considerar que en este punto se haya levantado la carga alegatoria que pesa sobre el recurrente: los recurrentes no han precisado de qué forma el art. 69 de la Ley 9/2007 vulnera las competencias autonómicas recogidas en esos preceptos estatutarios". Y es que, tanto la representación procesal de la Junta de Andalucía como la del Parlamento andaluz, en sus correspondientes escritos ya habían advertido de determinadas acusaciones manifiestamente infundadas que contenía el recurso.

Por lo que respecta a los motivos impugnatorios respecto a los cuales los recurrentes sí cumplieron su deber de alegar en Derecho, la Sentencia se centra en el núcleo de la discusión: la pretendida vulneración del art. 9.2 EBEP ${ }^{15}$. Indica el Tribunal Constitucional que este precepto "se limita a reservar al personal funcionario el ejercicio de determinadas funciones, que se delimitan mediante cláusulas generales — "funciones que impliquen la participación directa o indirecta en el ejercicio de las potestades públicas o en la salvaguarda de los intereses generales del Estado o de las Administraciones Públicas”-, y atribuye a las leyes autonómicas de desarrollo de cada Administración pública la fijación de los "términos" en los que se lleve a cabo ese ejercicio. Esta habilitación para el desarrollo legislativo del precepto se puede entender que incluye tanto la precisión de las concretas funciones que debe corresponder exclusivamente al personal funcionario como la determinación de las modalidades según las cuales los funcionarios pueden desarrollar las referidas funciones".

Para el Constitucional, "la mera lectura del párrafo primero del apartado 3 del art. 69 de la Ley 9/2007 permite descartar la existencia de la vulneración alegada", dado que el mismo se limita a establecer una previsión normativa que se inserta en el círculo descrito por

3. En el caso de que se trate de funciones que impliquen la participación directa o indirecta en el ejercicio de las potestades públicas o en la salvaguarda de los intereses generales que deban corresponder exclusivamente a personal funcionario de acuerdo con la legislación aplicable en materia de función pública, podrá llevarlas a cabo, bajo la dirección funcional de la agencia pública empresarial, el personal funcionario perteneciente a la Consejería o la agencia administrativa a la que esté adscrita. A tal fin, se configurarán en la relación de puestos de trabajo correspondiente las unidades administrativas precisas, que dependerán funcionalmente de la agencia pública empresarial.

La dependencia de este personal supondrá su integración funcional en la estructura de la agencia, con sujeción a las instrucciones y órdenes de servicio de los órganos directivos de la misma, quienes ejercerán las potestades que a tal efecto establece la normativa general. El decreto por el que se aprueben los estatutos de la agencia contendrá las prescripciones necesarias para concretar el régimen de dependencia funcional, el horario de trabajo y las retribuciones en concepto de evaluación por desempeño y las relativas al sistema de recursos administrativos que procedan contra los actos que se dicten en ejercicio de las potestades administrativas atribuidas a la agencia."

${ }^{15}$ El art. 9.2 del Real Decreto Legislativo 5/2015 establece lo siguiente: "En todo caso, el ejercicio de las funciones que impliquen la participación directa o indirecta en el ejercicio de las potestades públicas o en la salvaguardia de los intereses generales del Estado y de las Administraciones Públicas corresponden exclusivamente a los funcionarios públicos, en los términos que en la ley de desarrollo de cada Administración Pública se establezca."

Revista Andaluza de Administración Pública

ISSN: 1130-376X, núm. 93, Sevilla, septiembre-diciembre (2015), págs. 177-201 
el EBEP y que -en el reverso de lo dicho por los recurrentes- "garantiza el efectivo cumplimiento de lo dispuesto en el art. 9.2 del Real Decreto Legislativo 5/2015".

Por lo que respecta a la cuestión de la atribución de potestades administrativas a agencias públicas empresariales cuyo personal se regirá por el derecho privado, el Constitucional indica que el art. 2.2 LRJAP y PAC no impide la atribución de potestades administrativas a las entidades instrumentales vinculadas o dependientes de las Administraciones públicas territoriales y que el citado precepto no prejuzga el régimen de organización y funcionamiento de las entidades de derecho público cuando no ejerzan potestades administrativas. Dicho esto, el art. 69 de la Ley 9/2007 expresamente excluye del régimen de derecho privado de las agencias públicas empresariales las cuestiones relacionadas con el ejercicio de las potestades administrativas que tengan atribuidas, por lo que se sitúa en el estricto cumplimiento del marco conformado por la norma básica. Y tampoco da el Tribunal la razón a los recurrentes cuando insisten en que la única interpretación posible del art. 9.2 EBEP es la de que sólo a las entidades que cuenten con personal funcionario se les puede atribuir potestades administrativas y que el personal funcionario que desempeñe esas funciones debe depender orgánicamente de la propia entidad en la que realizan su actividad. Como indica el alto tribunal, esta interpretación "puede sin duda resultar razonable, pero eso no significa que sea la única posible", ya que dentro del margen de desarrollo legislativo que en esta materia le reconocen expresamente el Estatuto de Autonomía de Andalucía (art. 76.1 EAAnd) y el propio art. 9.2 del Real Decreto Legislativo 5/2015, el Legislador autonómico ha previsto la posibilidad de la adscripción funcional de funcionarios dependientes orgánicamente de la Administración pública territorial como fórmula para proporcionar a las agencias públicas empresariales autonómicas el personal funcionario legalmente necesario para realizar las funciones anteriormente mencionadas.

En su empeño por agotar todas las vías de ataque a la adscripción funcional de funcionarios, los recurrentes argumentaron que la Ley impugnada afecta al carácter básico de las condiciones de movilidad de los funcionarios porque la misma encubre un supuesto de movilidad forzosa. A este respecto y tras recordar el Tribunal Constitucional que la disociación entre dependencia orgánica y dependencia funcional del personal funcionario no es extraña en nuestro ordenamiento jurídico-administrativo (incluso entre diferentes poderes públicos, como acontece con la policía judicial), niega la existencia de movilidad forzosa toda vez que, en el régimen previsto en la Ley de Reordenación, el funcionario permanece en su puesto de trabajo, sin que exista remoción o cambio de puesto de trabajo.

En un siguiente motivo de impugnación, los recurrentes consideran que la previsión legal de que el personal de las agencias sea contratado (en las agencias públi- 
cas empresariales), o pueda ser tanto funcionario como personal laboral (en las agencias de régimen especial), vulnera la preferencia constitucional por el régimen funcionarial. Mas, a juicio del Constitucional, la interpretación correcta del art. 74.1 de la Ley 9/2007 es la que no establece una preferencia por el régimen laboral del personal al servicio de las agencias andaluzas, sino que se limita a promulgar una regla general de autorización indistinta de personal tanto funcionario como contratado en las agencias de régimen especial y una regla especial que reserva al personal funcionario las funciones que impliquen ejercicio de autoridad, razón por la cual también se desestima este motivo de recurso.

A continuación, analiza el Tribunal Constitucional la alegada lesión del contenido esencial de los derechos fundamentales reconocidos en los arts. 14 y $23.2 \mathrm{CE}$ por no determinar el régimen de integración del personal afectado por la reordenación. Tras un detenido repaso por la doctrina constitucional, el alto tribunal concluye que, ya sea a partir del art. 23.2 CE o del art. $14 \mathrm{CE}$ "resulta aplicable un canon parcialmente equivalente de enjuiciamiento, con independencia del carácter funcionarial o laboral del personal afectado, en la medida en que la igualdad que garantiza el art. 23.2 CE en el acceso a las funciones públicas que desempeña el personal estatutario constituye una especificación del principio de igualdad que garantiza el art. 14 CE en el conjunto de las funciones públicas. A partir de ese canon común, quienes tengan la condición de funcionario disfrutan además de la protección que ofrece la garantía de la predeterminación normativa que consagra el art. 23.2 CE”.

Sentado tal canon, se analiza si éste se cumple en la Ley 1/2011. Aprecia el Constitucional que la misma contiene una serie de reglas generales y abstractas que necesitan ser concretadas por la Administración en un protocolo, previa consulta y negociación con los órganos de representación del personal y tras recabar el informe de diversos órganos administrativos. Mas el Tribunal opina que los recurrentes no habían llegado a alegar ningún indicio o elemento que permita fundamentar el juicio de que los criterios establecidos por aquella no son constitucionalmente adecuados, llegando incluso a invocar como razón jurídica, meras hipótesis. De contrario, la sentencia que se glosa afirma que la disposición adicional cuarta de tal ley cumple suficientemente la exigencia de predeterminación normativa que dimana del art. 23.2 CE, al establecer con carácter general y de forma previa los requisitos de integración en las nuevas agencias que deberá aplicar la Administración sobre los funcionarios públicos. Y en segundo lugar, las reglas que establece "son objetivas, no tienen en cuenta situaciones individuales ni incluyen referencias individualizadas o ad personam y no abren la puerta a la asignación de puestos de trabajo con desprecio de los principios de mérito y capacidad".

Finalmente, se impugna la disposición derogatoria única, por derogar expresamente una norma básica, en concreto el art. 9.2 EBEP. Mas, "es evidente que una norma 
autonómica no puede derogar una norma estatal básica, ni de forma directa, ni mediante el expediente de derogar la norma autonómica que la reproduce. Las relaciones entre el ordenamiento jurídico estatal y el autonómico no se rigen por el principio de jerarquía, sino por el principio de competencia. Todo lo más, una norma autonómica puede contradecir una norma estatal básica, incurriendo con ello en inconstitucionalidad mediata, siempre que la norma estatal sea efectivamente básica en el doble sentido, formal y material, requerido por la doctrina constitucional. Pero, como ya hemos indicado, eso no ocurre en el presente caso con respecto al art. 9.2 del Real Decreto Legislativo 5/2015".

En conclusión, el resultado es una sentencia extensa, clara y terminante en sus postulados que desestima al completo todos y cada uno de los motivos alegados por los recurrentes, diputados integrantes del Partido Popular, tanto respecto de la totalidad de la ley como de los concretos preceptos impugnados. Con ello, se ratifica la constitucionalidad de la Ley 1/2011.

\section{Los votos particulares}

La Sentencia contó con el voto particular de dos Magistrados, los Sres. González-Trevijano Sánchez y González Rivas, quien se adhirió al voto del anterior.

Considera el voto particular que la Ley 1/2011 constituye "la manifestación más contundente de un fenómeno que ha sido objeto de abundante debate y crítica por la doctrina más autorizada y por la jurisprudencia administrativa, y que se conoce con el nombre de "huida del Derecho Administrativo" "16. Tras realizar una detenida disertación sobre esta cuestión -ciertamente, central en el debate administrativista- critican estos Magistrados que la Ley abra "una posibilidad cierta de transferencia de la gestión ordinaria de la Administración de la Junta de Andalucía a estas denominadas agencias públicas empresariales, mediante el diseño de un sistema administrativo que viene a conceder preferencia a entidades que, aún bajo formas de personificación pública, actúan fundamentalmente en régimen de derecho privado y con personal sometido a derecho laboral".

Con todo ello, mas "sin prejuzgar cuál habría debido ser el sentido del fallo", para estos Magistrados la Sentencia "debería - al menos - haberse planteado una legítima duda sobre la constitucionalidad de una ley que apuesta por una gestión generalizada de las competencias ordina-

16 ...O quizá no toda la doctrina. Para FERNÁNDEZ LUQUE, F las normas del Decreto-Ley suponen "en cierta medida, un alcance del Derecho Administrativo a las entidades de derecho público", siendo las entidades instrumentales privadas las "formas jurídicas más damnificadas" "La Administración instrumental: el objeto social en las sociedades mercantiles públicas de la Junta de Andalucía”, págs. 151 y ss. (Instituto Andaluz de Administración Pública, 2010). 
rias de la Administración de la Junta de Andalucía a través de entidades instrumentales de naturaleza empresarial, que cumplen funciones propias de las Administraciones públicas, mediante la regulación de una figura hibrida que, a través de una confusa referencia a la doctrina de los actos separables, no viene sino a elaborar en favor de estas entidades una especie de "traje a medida", que pretende aunar las ventajas de la atribución de potestades propias del poder público, sin los inconvenientes de la sujeción plena a las garantías del Derecho público, y, con ello, a remodelar las instituciones hasta hacerlas irreconocibles. La mera referencia apodíctica al art. 103.1 CE, que se realiza en el fundamento jurídico 5 c), resulta a todas luces insuficiente y obvia el necesario examen doctrinal que, en mi opinión, debería haberse realizado."

Si se nos permite la licencia, se trata de una "particular" forma de emitir un voto particular, el cual no aventura el sentido del fallo pretendido, sino que -pareceapunta a una perspectiva metodológica, en el sentido de considerar que hubiera sido necesaria una mayor reflexión sobre el régimen jurídico que se crea para las agencias públicas empresariales.

\section{A MODO DE CODA}

Cinco años después de ser aprobada, la Ley 1/2011 encuentra el respaldo constitucional que determinados sectores pusieron en duda. Con ello, la Comunidad Autónoma Andaluza se sitúa en condiciones de paridad con el resto de Administraciones -General del Estado, autonómicas y locales- que, como ella, han reordenado su sector público para acomodarlo a las necesidades sociales y económicas actuales. En realidad, el hecho de que las recetas empleadas en el común de los casos sean similares (lógicamente, adecuándose a cada contexto normativo) da la razón a quienes consideraron desmesurado -cuanto no, artificial- el conflicto jurídico particularmente suscitado en torno a la reordenación del sector público andaluz.

Tras esta Sentencia debería cesar el debate acerca de las intenciones y los logros de la Ley 1/2011: la misma es piedra angular de un proceso -esperemos que aún por completar- de reordenación que ha supuesto la supresión de sociedades mercantiles y fundaciones instrumentales o su transformación en agencias públicas y que posibilita que el personal funcionario acceda al desempeño de sus funciones reservadas pero, en la práctica, realizadas por personal laboral de las citadas sociedades mercantiles y fundaciones.

Y esto, simplemente, es una (insistimos, inacabada) vuelta al Derecho Administrativo. 